\title{
In vitro antifungal susceptibilities and molecular typing of sequentially isolated clinical Cryptococcus neoformans strains from Croatia
}

\begin{abstract}
Correspondence
Emilija Mlinarić-Missoni emilija.mlinaric-missoni@hzjz.hr
\end{abstract}

Received 13 February 2011 Accepted 26 May 2011

\author{
Emilija Mlinarić-Missoni, ${ }^{1} \dagger$ Ferry Hagen, ${ }^{2,3}$ † William H. M. Chew, ${ }^{4}$ \\ Verica Važić-Babić, ${ }^{1}$ Teun Boekhout ${ }^{2,3}$ and Josip Begovac ${ }^{4,5}$
}

\author{
${ }^{1}$ Croatian National Institute of Public Health, Reference Centre for Diagnostics of Systemic \\ Mycoses, Zagreb, Croatia \\ ${ }^{2}$ CBS Fungal Biodiversity Centre, Department of Yeast and Basidiomycete Research, Utrecht, \\ The Netherlands \\ ${ }^{3}$ Department of Internal Medicine and Infectious Diseases, University Medical Center, Utrecht, \\ The Netherlands \\ ${ }^{4}$ University Hospital for Infectious Diseases, Zagreb, Croatia \\ ${ }^{5}$ Department of Infectious Diseases, University of Zagreb School of Medicine, Zagreb, Croatia
}

\begin{abstract}
A collection of 48 clinical Cryptococcus neoformans isolates from Croatia was investigated retrospectively using in vitro antifungal susceptibility testing and molecular biological techniques to determine mating type and serotype by PCR and amplified fragment length polymorphism (AFLP) genotyping. These isolates were obtained from 15 patients: ten were human immunodeficiency virus (HIV)-negative (66.7\%) and five were HIV-positive (33.3\%). From five patients, only one isolate was available, whilst from the other ten patients, two to 11 isolates were isolated sequentially. Antifungal susceptibility was tested by a broth microdilution method.

Serotype A (genotype AFLP1) and serotype D (genotype AFLP2) were both found in six patients (40\% each), and serotype AD (genotype AFLP3) in three (20.0\%) patients. Mating type $\alpha(n=12$; $80.0 \%$ ) predominated and $\alpha /$ a hybrids were identified in $20.0 \%$ of patients diagnosed with cryptococcosis. Two AFLP genotypes of $C$. neoformans were isolated during a single episode from one patient. The in vitro antifungal $\mathrm{MIC}_{90}$ and susceptibility ranges for $\mathrm{C}$. neoformans isolates were $0.5 \mu \mathrm{g} \mathrm{ml}^{-1}$ (range $0.031-0.5 \mu \mathrm{g} \mathrm{ml}^{-1}$ ) for amphotericin $\mathrm{B}, 4 \mu \mathrm{g} \mathrm{ml}^{-1}$ (range 1-4 $\mu \mathrm{g} \mathrm{ml}^{-1}$ ) for flucytosine and fluconazole, $0.25 \mu \mathrm{g} \mathrm{ml}^{-1}$ (range $0.031-0.5 \mu \mathrm{g} \mathrm{ml}^{-1}$ ) for itraconazole and $0.062 \mu \mathrm{g} \mathrm{ml}^{-1}$ (range $0.031-0.25 \mu \mathrm{g} \mathrm{ml}^{-1}$ ) for voriconazole.
\end{abstract}

\section{INTRODUCTION}

Cryptococcosis is a life-threatening systemic fungal infection caused by the opportunistic pathogenic yeast Cryptococcus neoformans or its primary pathogenic sibling Cryptococcus gattii. Worldwide, C. neoformans is the major cause of cryptococcosis in individuals with an underlying immunological disorder, such as patients that are infected with human immunodeficiency virus (HIV), who have undergone solid organ transplantation (Bovers et al., 2008; Warkentien \& Crum-Cianflone, 2010) or who have haematological malignancies (Bassetti et al., 2009; Vigouroux et al., 2000).

†These authors contributed equally to this work.

Abbreviations: AFLP, amplified fragment length polymorphisms; CSF, cerebrospinal fluid; HAART, highly active antiretroviral therapy; HIV, human immunodeficiency virus; i.v., intravenous; RCDSM, Reference Centre for Diagnostics of Systemic Mycoses; UHID, University Hospital of Infectious Diseases.
It has been estimated recently that the global burden of HIVassociated cryptococcosis approximates to 1 million cases annually (Park et al., 2009). In Croatia, from 1985, when HIV was diagnosed for the first time, up until December 2009, nearly $800 \mathrm{HIV}$-infected persons were registered (http:/www. hzjz.hr; data accessed 24 December 2010). Croatia has a centralized system of healthcare for HIV/acquired immunodeficiency syndrome patients who are all treated at the University Hospital of Infectious Diseases (UHID) in Zagreb. Since 1998, HIV-positive patients at this hospital have been treated with highly active antiretroviral therapy (HAART). Extrapulmonary cryptococcosis is an important opportunistic infection and was found in $29(8.7 \%)$ of the 332 HIV-positive patients treated at the UHID in the period 1986-2010.

The most frequent and severe clinical presentation of cryptococcosis is a disseminated meningoencephalitis, 
which is almost uniformly fatal if not diagnosed and treated appropriately. In addition to the traditional antifungal compounds amphotericin $\mathrm{B}$, lipid amphotericin B formulations, flucytosine, fluconazole, itraconazole and their combinations, treatment options for cryptococcosis have been increased by the expanded-spectrum azoles voriconazole and posaconazole (Perfect et al., 2010).

The application of molecular biological methods, such as PCR fingerprinting, PLB1 and URA5 RFLP fingerprinting, amplified fragment length polymorphism (AFLP) fingerprinting and multi-locus sequence typing, has led to a better insight into the taxonomy and identification of the causative agents of cryptococcosis (Bovers et al., 2008; Meyer et al., 2009). Within C. neoformans, three varieties can be distinguished: var. grubii (serotype A, AFLP genotype 1), var. neoformans (serotype D, AFLP genotype 2 ) and a hybrid between these two varieties (serotype $A D$, AFLP genotype 3). A third variety, C. neoformans var. gattii, has been raised to the species level and named $C$. gattii (Kwon-Chung et al., 2002). C. gattii (serotypes B and C, AFLP genotypes 4-7 and 10) predominantly causes infections in apparently immunocompetent individuals (Bovers et al., 2008; Hagen et al., 2010).

Epidemiological surveys provide a better understanding of the population dynamics of C. neoformans and C. gattii, as visualized by the ongoing C. gattii outbreak (Kidd et al., 2004). The epidemiology of $C$. neoformans has been studied intensively in western and Mediterranean Europe (DesnosOllivier et al., 2010; Guinea et al., 2010; van Elden et al., 2000; Viviani et al., 2006). However, there has been a lack of epidemiological studies on the occurrence of cryptococcosis in eastern Europe. Therefore, we initiated a retrospective study to investigate the epidemiology of cryptococcosis among Croatian citizens, as well as the molecular characterization and in vitro antifungal susceptibility profiles of the Cryptococcus isolates obtained.

\section{METHODS}

Isolates and patients. In total, 48 C. neoformans isolates, obtained from cerebrospinal fluid (CSF; $n=46)$, blood $(n=1)$, and sputum samples $(n=1)$ of 15 patients during the period February 2005 to February 2010, were studied retrospectively (Table 1). All cryptococcal infections were diagnosed at the Reference Centre for Diagnostics of Systemic Mycoses (RCDSM) at the Croatian National Institute of Public Health in Zagreb, Croatia. There were five HIV-infected patients and ten non-HIV-related immunodeficient patients. The latter were patients with haematological malignancies $(n=9)$ and one patient with idiopathic $\mathrm{CD} 4{ }^{+}$lymphocytopenia. The median age of the patients was 54 years (range 24-71 years). The five HIV-infected patients had a median CD4 ${ }^{+}$T-cell count of $27 \mathrm{~mm}^{-3}$ (range 15-51 $\mathrm{mm}^{-3}$ ). Fourteen patients had meningitis and one had cryptococcaemia without meningitis. The majority of the patients were treated at UHID $(n=11)$, whilst two were treated at the Dubrava Clinical Hospital in Zagreb and two at the Varaždin General Hospital. The patients from UHID were treated initially with a combination of amphotericin B and fluconazole $(n=5)$, sequential amphotericin B and fluconazole $(n=4)$ or fluconazole only $(n=2)$. The four HIVnegative patients hospitalized in two other hospitals did not receive antifungal treatment because cryptococcosis was diagnosed postmortem.

Samples were taken in accordance with clinical indications. All available isolates from each patient were analysed. One C. neoformans isolate was obtained from five patients, whilst from ten patients, between two and 11 isolates were recovered (Table 1). From nine patients, 46 Cryptococcus isolates were obtained during a single episode of cryptococcosis. The longest time span between the isolation of the first and last C. neoformans isolate was 58 days, with a mean of 14 days. From one patient, two isolates were obtained during two episodes of cryptococcosis, which were separated by a 130 day period (Table 1).

Isolates kept at the Culture Collection of the RCDSM were stored at $-80{ }^{\circ} \mathrm{C}$ using the Microbank system (Pro-Lab Diagnostics). All isolates were deposited in the public culture collection of the CBSKNAW Fungal Biodiversity Centre under accession numbers CBS 11956-11997 and CBS 11999-12004.

Media and identification. The initial diagnosis of cryptococcosis was made by direct examination of CSF samples with India ink preparation and by detection of capsular antigen in CSF and/or serum samples with a latex agglutination test (Pastorex Crypto Plus; BioRad). Cryptococcal isolation was carried out using Sabouraud's glucose agar and brain-heart infusion agar (BD Diagnostics). The ID32C method (bioMérieux) and morphology on cornmeal agar (BD Diagnostics) were used for the identification of $C$. neoformans isolates.

Antifungal susceptibility testing procedures. In vitro antifungal susceptibility profiles of Cryptococcus isolates were determined by a broth microdilution method according to the Clinical and Laboratory Standards Institute guidelines (CLSI, 2008). The antifungal agents were obtained directly from the manufacturers and comprised amphotericin B and flucytosine (Sigma Aldrich), fluconazole and voriconazole (Pfizer Pharmaceuticals) and itraconazole (Jansen Pharmaceutica). Briefly, powdered forms of each antifungal compound were dissolved in appropriate solvents to prepare stock solutions following the recommendations of CLSI (2008). Final antifungal concentrations ranged from 0.062 to $64 \mu \mathrm{g} \mathrm{ml}^{-1}$ for fluconazole, from 0.031 to $16 \mu \mathrm{g} \mathrm{ml}^{-1}$ for amphotericin $\mathrm{B}$ and flucytosine, and from 0.016 to $8 \mu \mathrm{g} \mathrm{ml}^{-1}$ for itraconazole and voriconazole. The test inoculum was adjusted to $1 \times 10^{3}$ c.f.u. $\mathrm{ml}^{-1}$.

Microdilution plates were incubated at $35{ }^{\circ} \mathrm{C}$ for $72 \mathrm{~h}$ and the MIC end points were subsequently determined visually as complete growth inhibition for amphotericin B and as a prominent decrease in turbidity $(\geqslant 50 \%)$ for the other antifungal agents compared with that for the growth control. Candida parapsilosis ATCC 22019/CBS 604 and Candida krusei ATCC 6258/CBS 573 were included as qualitycontrol strains.

According to recent studies, C. neoformans isolates can be considered resistant when the MIC values are $\geqslant 2 \mu \mathrm{g} \mathrm{ml}^{-1}$ for amphotericin B, $\geqslant 32 \mu \mathrm{g} \mathrm{ml}^{-1}$ for flucytosine, $\geqslant 16 \mu \mathrm{g} \mathrm{ml}^{-1}$ for fluconazole, and $\geqslant 1 \mu \mathrm{g} \mathrm{ml}^{-1}$ for itraconazole and voriconazole (Almeida et al., 2007; Guinea et al., 2010; Hagen et al., 2010; Perfect et al., 2010; Pfaller et al., 2005; Souza et al., 2005).

Mating type, serotype and genotype determination. Four different PCRs, using primers specific for each of the four mating type and serotype combinations $(\mathbf{a A}, \alpha \mathrm{A}, \mathrm{aD}$ and $\alpha \mathrm{D})$, were performed to determine the mating type and serotype of the $C$. neoformans isolates by partial amplification of the STE2O locus (Barreto de Oliveira et al., 2004). Amplification reactions were carried

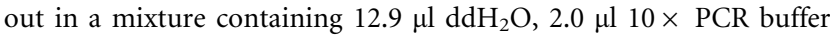
(15 mM MgCl 2 pH 8.3), $2.0 \mu \mathrm{l}$ dNTPs ( $1 \mathrm{mM}$; Bioline), $1.0 \mu \mathrm{l}$ each 
Table 1. Clinical data, source, days since the first positive culture, serotype, AFLP genotype and MIC values $\left(\mu \mathrm{ml}^{-1}\right)$ of the five tested antifungal compounds for each isolate

\begin{tabular}{|c|c|c|c|c|c|c|c|c|c|c|c|c|}
\hline Isolate & Patient & Sex & $\begin{array}{l}\text { HIV } \\
\text { status }\end{array}$ & Source & $\begin{array}{c}\text { Hospitalized } \\
\text { day }\end{array}$ & Serotype & AFLP & AMB & $5 \mathrm{FC}$ & FLU & ITR & VOR \\
\hline 1 & 1 & F & $\mathrm{HIV}^{+}$ & CSF & 0 & $\alpha \mathrm{A}$ & 1 & 0.062 & 1 & 2 & 0.250 & 0.062 \\
\hline 3 & & & & CSF & 2 & $\alpha \mathrm{A}$ & 1 & 0.062 & 1 & 2 & 0.250 & 0.062 \\
\hline 4 & & & & CSF & 3 & $\alpha \mathrm{A}$ & 1 & 0.062 & 1 & 2 & 0.250 & 0.062 \\
\hline 7 & 2 & M & $\mathrm{HIV}^{-}$ & CSF & 0 & $\alpha \mathrm{A}$ & 1 & 0.500 & 1 & 4 & 0.500 & 0.031 \\
\hline 8 & 3 & M & $\mathrm{HIV}^{-}$ & CSF & 0 & $\alpha \mathrm{D}-\mathrm{aA}$ & 3 & 0.062 & 2 & 4 & 0.125 & 0.062 \\
\hline 9 & & & & CSF & 130 & $\alpha \mathrm{D}-\mathbf{a A}$ & 3 & 0.500 & 4 & 4 & 0.125 & 0.125 \\
\hline 10 & 4 & M & $\mathrm{HIV}^{-}$ & CSF & 0 & $\alpha \mathrm{D}$ & 2 & 0.125 & 4 & 2 & 0.125 & 0.031 \\
\hline 11 & & & & CSF & 1 & $\alpha \mathrm{D}$ & 2 & 0.125 & 4 & 2 & 0.125 & 0.031 \\
\hline 12 & & & & CSF & 2 & $\alpha \mathrm{D}$ & 2 & 0.125 & 4 & 2 & 0.125 & 0.031 \\
\hline 16 & & & & CSF & 1 & $\alpha \mathrm{D}$ & 2 & 0.125 & 4 & 1 & 0.125 & 0.062 \\
\hline 17 & & & & CSF & 2 & $\alpha \mathrm{D}$ & 2 & 0.125 & 4 & 1 & 0.125 & 0.062 \\
\hline 18 & & & & CSF & 6 & $\alpha \mathrm{D}$ & 2 & 0.125 & 4 & 1 & 0.125 & 0.062 \\
\hline 19 & 7 & M & $\mathrm{HIV}^{+}$ & CSF & 0 & $\alpha \mathrm{D}$ & 2 & 0.062 & 1 & 1 & 0.031 & 0.062 \\
\hline 20 & & & & CSF & 1 & $\alpha \mathrm{D}$ & 2 & 0.062 & 1 & 1 & 0.031 & 0.062 \\
\hline 21 & & & & CSF & 2 & $\alpha \mathrm{D}$ & 2 & 0.062 & 1 & 1 & 0.031 & 0.062 \\
\hline 22 & & & & CSF & 14 & $\alpha \mathrm{D}$ & 2 & 0.062 & 2 & 2 & 0.125 & 0.062 \\
\hline 23 & & & & CSF & 21 & $\alpha \mathrm{D}$ & 2 & 0.125 & 2 & 2 & 0.125 & 0.062 \\
\hline 24 & & & & CSF & 28 & $\alpha \mathrm{D}$ & 2 & 0.125 & 4 & 2 & 0.125 & 0.062 \\
\hline 25 & & & & CSF & 34 & $\alpha \mathrm{D}$ & 2 & 0.250 & 4 & 2 & 0.125 & 0.062 \\
\hline 26 & & & & CSF & 39 & $\alpha \mathrm{D}$ & 2 & 0.250 & 4 & 2 & 0.125 & 0.062 \\
\hline 35 & & & & Sputum & 13 & $\alpha \mathrm{D}$ & 2 & 0.125 & 4 & 1 & 0.062 & 0.062 \\
\hline 36 & 11 & $\mathrm{~F}$ & $\mathrm{HIV}^{-}$ & CSF & 0 & $\alpha \mathrm{A}$ & 1 & 0.062 & 4 & 1 & 0.062 & 0.062 \\
\hline 37 & & & & CSF & 1 & $\alpha \mathrm{A}$ & 1 & 0.062 & 4 & 1 & 0.062 & 0.062 \\
\hline 38 & & & & CSF & 2 & $\alpha \mathrm{A}$ & 1 & 0.062 & 4 & 1 & 0.062 & 0.062 \\
\hline 39 & & & & CSF & 4 & $\alpha \mathrm{A}$ & 1 & 0.062 & 4 & 1 & 0.062 & 0.062 \\
\hline 40 & & & & CSF & 5 & $\alpha \mathrm{A}$ & 1 & 0.062 & 4 & 1 & 0.062 & 0.062 \\
\hline 41 & 12 & M & $\mathrm{HIV}^{-}$ & CSF & 0 & $\alpha \mathrm{A}$ & 1 & 0.500 & 4 & 4 & 0.500 & 0.031 \\
\hline 42 & 13 & $\mathrm{~F}$ & $\mathrm{HIV}^{-}$ & CSF & 0 & $\alpha \mathrm{D}$ & 2 & 0.062 & 4 & 1 & 0.062 & 0.062 \\
\hline 43 & & & & CSF & 1 & $\alpha \mathrm{D}$ & 2 & 0.062 & 4 & 1 & 0.062 & 0.062 \\
\hline 44 & & & & CSF & 13 & $\alpha \mathrm{D}$ & 2 & 0.125 & 4 & 1 & 0.062 & 0.062 \\
\hline 45 & 14 & M & $\mathrm{HIV}^{-}$ & CSF & 0 & $\alpha \mathrm{D}$ & 2 & 0.500 & 4 & 2 & 0.062 & 0.031 \\
\hline 46 & 15 & M & $\mathrm{HIV}^{+}$ & CSF & 0 & $\alpha \mathrm{A}-\mathrm{aD}$ & 3 & 0.062 & 4 & 2 & 0.062 & 0.125 \\
\hline 47 & & & & CSF & 12 & $\alpha \mathrm{A}-\mathrm{aD}$ & 3 & 0.062 & 4 & 4 & 0.125 & 0.125 \\
\hline 48 & & & & CSF & 18 & $\alpha \mathrm{A}-\mathrm{aD}$ & 3 & 0.062 & 4 & 4 & 0.125 & 0.250 \\
\hline
\end{tabular}

primer $\left(10 \mathrm{pmol} \mu \mathrm{l}^{-1}\right), 0.1 \mu \mathrm{l}$ Taq DNA polymerase $\left(5 \mathrm{U}^{-1}\right.$; Bioline) and $1.0 \mu \mathrm{l}$ genomic DNA $\left(100 \mathrm{ng}^{-1} \mathrm{l}^{-1}\right)$. Reference strains 125.91 (=CBS 10512; aA, AFLP1), H99 (=CBS 8710; $\alpha$ A, AFLP1), JEC20 (=CBS 10511; aD, AFLP2) and JEC21 (=CBS 10513; $\alpha \mathrm{D}$, AFLP2) were included as controls.
AFLP fingerprinting was performed to genotype the isolates as described previously (Barreto de Oliveira et al., 2004; Boekhout et al., 2001). The reference strains H99 (=CBS 8710; AFLP1), Bt63 (=CBS 11550; AFLP1A), WM626 (=CBS 10083; AFLP1B), JEC21 (=CBS 10513; AFLP2), CBS 132 (AFLP3), WM179 (=CBS 10078; AFLP4), 
WM161 (=CBS 10081; AFLP5), WM178 (=CBS 10082; AFLP6), WM779 (=CBS 10101; AFLP7), CBS 10488 (AFLP8), CBS 10496 (AFLP9) and CBS11687 (AFLP10) were included to assign AFLP genotypes to each of the clinical isolates (Hagen et al., 2010; Meyer et al., 2009).

Statistical analysis of results. The $\mathrm{MIC}_{50}, \mathrm{MIC}_{90}$ and geometric mean MIC values of each antifungal agent were calculated. Only the first isolate for every patient was used in the analysis of the relationship between in vitro susceptibility to the five tested antifungal compounds and the patients' immune status and the different mating types, serotypes and genotypes of C. neoformans isolates. To compare two groups, the Mann-Whitney test was applied, whilst the KruskalWallis test was used to compare more than two groups. Statistical analyses were performed using SPSS version 12 (SPSS), and statistical significance was determined when a value of $P<0.05$ was observed.

\section{RESULTS}

\section{Mating type, serotype and AFLP genotype analyses}

PCR-based mating type and serotype determination revealed that cryptococcosis in the majority of patients was caused by mating type $\alpha(n=12 ; 80.0 \%)$, whilst the remaining three $(20.0 \%)$ patients were found to be infected by cryptococcal isolates with the mating types $\alpha$ and a (Table 1). Combined with the serotype of these isolates, it was found that six $(40.0 \%)$ patients were infected with $\alpha \mathrm{A}$, another six $(40.0 \%)$ with $\alpha \mathrm{D}$, two $(13.3 \%)$ with $\alpha \mathrm{A}-\mathrm{aD}$ and one (6.7\%) patient with $\alpha \mathrm{D}-\mathrm{aA}$. The frequency of cryptococcosis caused by genotype AFLP1 and AFLP2 isolates was $40.0 \%$ each (six patients each), whilst genotype AFLP3 isolates were observed to have infected three patients $(20.0 \%)$.

AFLP fingerprinting revealed more diversity among isolates that were isolated from the same patient (Fig. 1). No discrepancies between the previously determined mating type and serotype results and the AFLP genotyping were observed.

None of the patients was found to be infected with $C$. neoformans isolates that had different mating types or serotypes (Fig. 1; Table 1). However, the AFLP fingerprint patterns showed that there were genotypic differences among isolates from the same patient. The majority of differences between 'same-patient isolates' were found to be minor changes in the AFLP fingerprint patterns, i.e. the absence or presence of minor fragments (Fig. 1). It was observed that patient 8 was infected with two different $C$. neoformans genotypes. The first two $C$. neoformans var. grubii isolates cultured from patient 8 were found to be genotypically similar, namely AFLP1B, whilst the third isolate from day 11 was found to belong to genotype AFLP1 (Fig. 1). Two out of 11 C. neoformans var. neoformans isolates from patient 7 , isolated on days 1 and 2 of hospitalization, were found to be genotypically slightly different from the other isolates that were isolated on the following 56 days, as indicated by the absence of some major fragments (Fig. 1). However, the C. neoformans var. neoformans isolate cultured on the first 2 days persisted, as a similar genotypic isolate was found in the CSF sample taken on day 39. Similar observations were made for the C. neoformans isolates cultured from patients 1 and 6. Six isolates were available from patient 1 : the isolate from the first day of hospitalization was found to be similar to those isolated 4 and 11 days after the first sample was taken. Genotypically slightly different isolates were cultured during the 3 days following the first sample. For patient 6 , the isolate on the first day of hospitalization had additional fragments in its AFLP fingerprint pattern compared with isolates cultured during successive days of isolation. Interestingly, the absence of two minor fragments in the AFLP fingerprint profile of the C. neoformans genotype AFLP3 isolates CRO08 and CRO09 cultured from patient 3 caused an apparent problem for the AFLP fingerprint clustering software, as these isolates clustered in different clades (Fig. 1).

\section{Antifungal susceptibility testing}

Detailed results of the broth microdilution antifungal susceptibility testing for all 48 clinical isolates have been summarized in Tables 1 and 2. All five antifungal compounds demonstrated high in vitro activity against all C. neoformans isolates. The $\mathrm{MIC}_{90}$ for amphotericin $\mathrm{B}$ was $0.5 \mu \mathrm{g} \mathrm{ml}^{-1}$, for flucytosine and fluconazole was $4 \mu \mathrm{g} \mathrm{ml}^{-1}$, for itraconazole was $0.25 \mu \mathrm{g} \mathrm{ml}^{-1}$ and for voriconazole was $0.062 \mu \mathrm{g} \mathrm{ml}^{-1}$. The MIC range for amphotericin B was $0.031-0.5 \mu \mathrm{g} \mathrm{ml}^{-1}$ and for flucytosine and fluconazole was $1-4 \mu \mathrm{g} \mathrm{ml}^{-1}$, whilst the MIC range of itraconazole was found to be broader $\left(0.031-0.5 \mu \mathrm{g} \mathrm{ml}^{-1}\right)$ than that of voriconazole $\left(0.031-0.25 \mu \mathrm{g} \mathrm{ml}^{-1}\right)$.

No significant differences in susceptibility to any of the five tested antifungal compounds were observed when the patients' HIV status, or the mating type, serotype or AFLP genotype of the $C$. neoformans isolates were analysed (Table 3).

\section{DISCUSSION}

The present retrospective study describes the epidemiology and in vitro antifungal susceptibility profiles of sequentially isolated C. neoformans strains from 15 Croatian patients during a 5 year period (2005-2010). This study was initiated due to the absence of any epidemiological data regarding Cryptococcus infections in Eastern Europe.

\section{In vitro antifungal susceptibility profiles}

The tested antifungal compounds amphotericin B, flucytosine, fluconazole, itraconazole and voriconazole demonstrated high in vitro activity against $C$. neoformans isolates (Table 1). The highest geometric mean MIC was found for flucytosine $\left(2.79 \mu \mathrm{g} \mathrm{ml}^{-1}\right)$ and the lowest for voriconazole $\left(0.06 \mu \mathrm{g} \mathrm{ml}^{-1}\right)$ (Table 2). Despite the increase in in vitro 


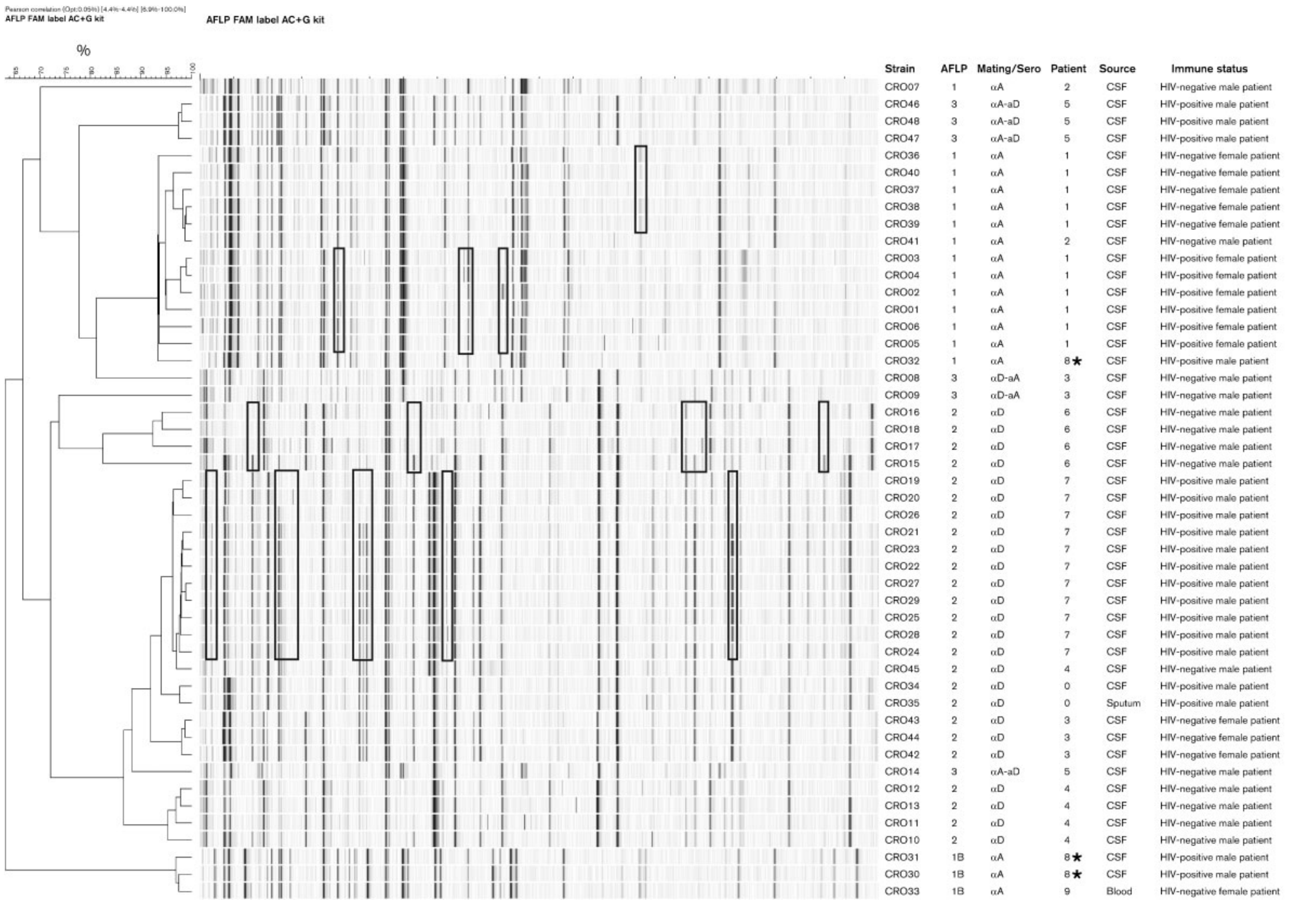

Fig. 1. AFLP fingerprint patterns of 48 Croatian C. neoformans isolates. AFLP genotype, mating type and serotype, patient number, source of isolation and HIV status of the patient, as well as the day of isolation during hospitalization, are indicated after the AFLP fingerprint pattern. Examples of differences in AFLP fingerprint patterns among sequential isolates of $C$. neoformans are indicated by a box. Three $C$. neoformans isolates that were isolated from patient 8 are indicated by asterisks to highlight the different AFLP genotypes that these isolates exhibited. 
Table 2. MIC ranges, geometric mean $\mathrm{MICs}, \mathrm{MIC}_{50}, \mathrm{MIC}_{90}$ and percentages of $\mathrm{C}$. neoformans isolates per $\mathrm{MIC}$ group

\begin{tabular}{|c|c|c|c|c|c|c|c|c|c|c|c|c|}
\hline \multirow[t]{2}{*}{ Antifungal } & \multicolumn{4}{|c|}{ MIC values $\left(\mu \mathrm{g} \mathrm{ml}^{-1}\right)$} & \multicolumn{8}{|c|}{ Percentage per MIC group $\left(\mu \mathrm{g} \mathrm{ml}^{-1}\right)$} \\
\hline & Range & $\mathrm{MIC}_{50}$ & $\begin{array}{l}\text { Geometric } \\
\text { mean MIC }\end{array}$ & $\mathrm{MIC}_{90}$ & 0.031 & 0.062 & 0.125 & 0.25 & 0.5 & 1 & 2 & 4 \\
\hline Amphotericin B & $0.031-0.5$ & 0.062 & 0.100 & 0.5 & 2.1 & 52.1 & 27.1 & 6.2 & 12.5 & - & - & - \\
\hline Flucytosine & $1-4$ & 4 & 2.788 & 4 & - & - & - & - & - & 18.7 & 14.6 & 66.7 \\
\hline Fluconazole & $1-4$ & 2 & 1.658 & 4 & - & - & - & - & - & 43.7 & 39.6 & 16.7 \\
\hline Voriconazole & $0.031-0.25$ & 0.062 & 0.059 & 0.062 & 16.7 & 75.0 & 6.2 & 2.1 & - & - & - & - \\
\hline
\end{tabular}

MIC values by $1-3 \log _{2}$ dilutions, the maximum MIC values for these sequential isolates obtained during the course of a single or multiple episodes of cryptococcosis remained susceptible in vitro to all tested antifungal agents (Table 1).

Similar to the clinical isolates of $C$. neoformans from Croatia, large percentages ( $99 \%)$ of tested clinical isolates from Africa, Europe, North America, South America and the Pacific Region (Pfaller et al., 2005), Cuba (IllnaitZaragozí et al., 2008), France (Dannaoui et al., 2006), Spain (Guinea et al., 2010; López-Jodra et al., 2000), Brazil (Almeida et al., 2007; Souza et al., 2005) and the USA (Brandt et al., 2001) were shown to be susceptible in vitro to amphotericin B (MIC $\leqslant 1 \mu \mathrm{g} \mathrm{ml}^{-1}$ ). However, detection of in vitro resistance to amphotericin B (MIC $\geqslant 2 \mu \mathrm{g} \mathrm{ml}^{-1}$ ) in $5.3 \%$ of the studied clinical C. neoformans isolates from a Spanish collection appeared to be different from the current study, as well as from the other aforementioned studies (Perkins et al., 2005).

In concordance with the results of the current study, previous studies have also found in vitro susceptibility of all investigated clinical $C$. neoformans isolates to itraconazole $\left(\mathrm{MIC} \leqslant 0.5 \mu \mathrm{g} \mathrm{ml}^{-1}\right.$ ) (Datta et al., 2003; López-Jodra et al., 2000; Souza et al., 2005) and voriconazole (MIC $\leqslant 0.5 \mu \mathrm{g} \mathrm{ml}^{-1}$ ) (Guinea et al., 2010; Illnait-Zaragozí et al., 2008; Perkins et al., 2005; Souza et al., 2005). Exceptions were the findings of in vitro resistance (MIC $\geqslant 1 \mu \mathrm{g} \mathrm{ml}^{-1}$ ) to itraconazole for $<10 \%$ of the studied $C$. neoformans isolates (Almeida et al., 2007; Brandt et al., 2001; IllnaitZaragozí et al., 2008) and even up to $15.8 \%$ for a group of Spanish C. neoformans isolates (Perkins et al., 2005).

The results of the in vitro testing for susceptibility to fluconazole and flucytosine for the Croatian clinical $C$. neoformans isolates are in concordance with other recent studies. For fluconazole, we observed MICs of $<16 \mu \mathrm{g} \mathrm{ml}^{-1}$, which is similar to data given by Almeida et al. (2007), Dannaoui et al. (2006) and Souza et al. (2005), whilst the MIC of $<32 \mu \mathrm{g} \mathrm{ml}^{-1}$ for flucytosine was similar to those found by Dannaoui et al. (2006) and López-Jodra et al. (2000). In contrast to this, in vitro resistance to fluconazole (MIC $\geqslant 16 \mu \mathrm{g} \mathrm{ml}^{-1}$ ) was proven in $3.4 \%$ of C. neoformans isolates originating from Spain (Guinea et al., 2010), $15.9 \%$ from India (Datta et al.,
2003), 19\% from the USA (Brandt et al., 2001), $25 \%$ from North America (Pfaller et al., 2005) and $46.6 \%$ from Spain (Perkins et al., 2005). The percentage of clinical C. neoformans isolates resistant to flucytosine (MIC $\geqslant 32 \mu \mathrm{g} \mathrm{ml}^{-1}$ ) was lower and also dependent on geographical area. Whilst all Croatian C. neoformans isolates were found to be susceptible to flucytosine, $1 \%$ of African, European, Pacific and North and South American isolates (Pfaller et al., 2005), $3.8 \%$ of isolates from the USA (Brandt et al., 2001) and $4.7 \%$ of isolates from Spain (Perkins et al., 2005) were observed to be resistant.

The difference in in vitro antifungal susceptibility between the different genotypes and mating types within $C$. neoformans has not been studied extensively. To the best of our knowledge, the current study is the second known, after that of Guinea et al. (2010). The current study (summarized in Table 3) and that of Guinea et al. (2010) observed that the genotypic background of a cryptococcal isolate (genotype AFLP 1-3) or the mating type $\alpha$ had no statistically significant influence on the in vitro antifungal activity against fluconazole and voriconazole. In contrast to our results (Table 3), the Spanish epidemiological study of Guinea et al. (2010) observed a statistically significant correlation of in vitro susceptibility to amphotericin B with the AFLP genotypes of the C. neoformans isolates.

Several studies have evaluated the relationships between antifungal susceptibility and serotypes of C. neoformans isolates. There was no significant difference observed between the antifungal susceptibility values to the five antifungal compounds when compared with the serotype $\mathrm{A}, \mathrm{D}$ and $\mathrm{AD}$ background of the isolates (Table 3). The French (Dannaoui et al., 2006) and Italian (Tortorano et al., 1997) studies showed that serotype A isolates were significantly less susceptible to fluconazole than serotype D. However, this discrepancy between serotypes A and D was not observed in the Spanish study (Guinea et al., 2010). The French (Dannaoui et al., 2006) and Spanish (Guinea et al., 2010) studies observed that in vitro antifungal susceptibility to amphotericin B was lower in serotype A than in serotype D isolates. The French C. neoformans serotype A isolates were also less susceptible to flucytosine than serotype D isolates (Dannaoui et al., 2006). In concordance with the results of the current study (Table 3), the susceptibility to fluconazole and voriconazole for 


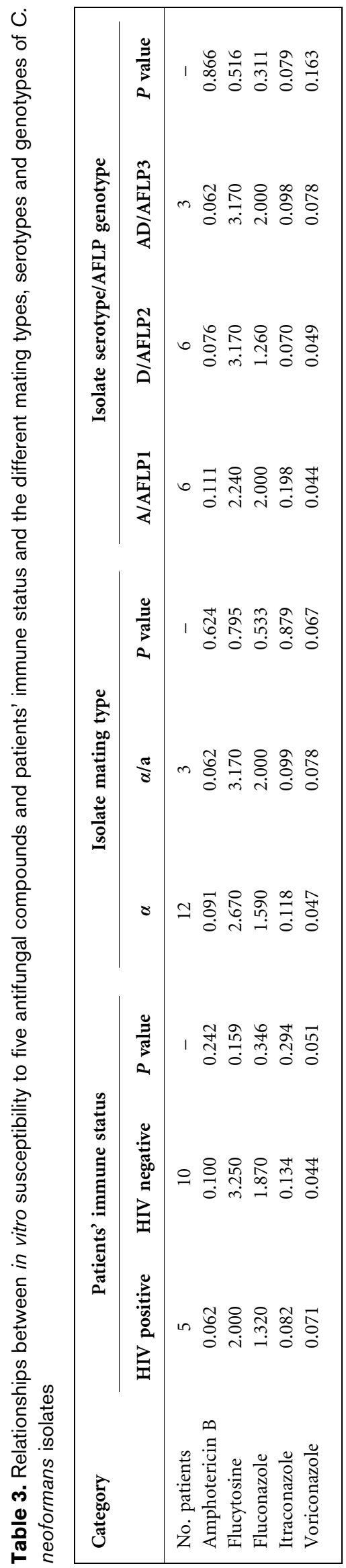

different serotypes of $C$. neoformans was similar to those observed in the Spanish study (Guinea et al., 2010).

\section{Sequential C. neoformans isolates from the same patient}

A handful of studies have been published that describe the occurrence of mixed C. neoformans infections or shifts in genotypic and antifungal susceptibility differences among sequentially isolated C. neoformans strains (Blasi et al., 2001; Casadevall et al., 1993; Desnos-Ollivier et al., 2010; Illnait-Zaragozí et al., 2010; Pfaller et al., 1998; Spitzer et al., 1993; Sullivan et al., 1996). It has been shown that genomic differences between sequential isolates of $C$. neoformans can influence virulence and persistence of a cryptococcal infection, as has been shown using a mouse pathogenicity model (Fries \& Casadevall, 1998). Besides a change in the genotype of the initial $C$. neoformans isolate due to microevolution or karyotype instability, replacement of the initial isolate with another genotypic variant can influence the outcome of antifungal treatment or may cause a relapse (Blasi et al., 2001; Fries \& Casadevall, 1998).

From the patients from whom we studied multiple $C$. neoformans isolates, only patient 8 was found to be infected with multiple genotypic $C$. neoformans variants, namely genotype AFLP1 and AFLP1B isolate (Fig. 1, indicated by asterisks). Several other patients (1,6 and 7) were found to be infected with isolates that showed minor differences in the AFLP fingerprint patterns. Interestingly, it was observed that the $11 \mathrm{C}$. neoformans var. neoformans isolates from patient 7 became gradually less susceptible, when tested in vitro, to amphotericin B $\left(0.062-0.5 \mu \mathrm{g} \mathrm{ml}^{-1}\right)$, flucytosine $\left(1-4 \mu \mathrm{g} \mathrm{ml}^{-1}\right)$, fluconazole $\left(1-2 \mu \mathrm{g} \mathrm{ml}^{-1}\right)$ and itraconazole $\left(0.031-0.125 \mu \mathrm{g} \mathrm{ml}^{-1}\right)$, whilst no change in voriconazole susceptibility was observed (Table 1). The gradual decrease in in vitro antifungal susceptibility of these isolates might be due to microevolution that took place in the C. neoformans isolates during the course of antifungal therapy undergone by this patient. Patient 7 was initially treated with intravenous (i.v.) colloidal amphotericin B $\left(400 \mathrm{mg} \mathrm{day}^{-1}\right)$ and fluconazole $\left(400 \mathrm{mg} \mathrm{day}^{-1}\right)$. After 3 weeks therapy, the dosage of fluconazole was doubled. Different formulations of amphotericin B were continuously given for a total of 2 months, after which a high dosage of fluconazole $\left(1600 \mathrm{mg} \mathrm{day}^{-1}\right.$ i.v. $)$ was administrated. HIV infection in patient 7 was confirmed after the diagnosis of cryptococcal meningitis. The patient had a $\mathrm{CD}^{+}$cell count of $25 \mathrm{~mm}^{-3}$ and a plasma RNA HIV-1 viral load of 956000 copies $\mathrm{ml}^{-1}$. HAART, with stavudine, lamivudine and nevirapine, was given after 3 weeks antifungal therapy. After 6 weeks HAART, the $\mathrm{CD}^{+}$cell count increased to $96 \mathrm{~mm}^{-3}$ and the plasma viral load decreased to 1490 HIV-1 RNA copies $\mathrm{ml}^{-1}$. However, the patient did not recover and died 3 months after the diagnosis of cryptococcal meningitis was made. HIVinfected patient 7 was shown to be infected initially with a C. neoformans var. neoformans isolate that was replaced by 
another genotypic variant after day 2, whilst the initial genotypic variant was again isolated on day 39 (Fig. 1, Table 1).

The case of patient 7 is comparable to results observed by Spitzer et al. (1993), who showed that initial and recurrent C. neoformans isolates were clonally related. This confirms that an initial $C$. neoformans isolate can persist despite antifungal therapy, rather than that a novel infection is acquired. Thus, therapeutic failure might occur because an antifungal treatment strategy cannot eradicate the initial infection (Spitzer et al., 1993). In contrast, it was also observed that sequential C. neoformans isolates became increasingly susceptible in vitro to fluconazole (Casadevall et al., 1993). This provides evidence against antifungal resistance as the cause of recurrent $C$. neoformans infection, and it might be that an attenuated immune system can give rise to the persistence of cryptococcal infections (Casadevall et al., 1993).

For the C. neoformans cultures from patient 8, higher MIC values were found between the two initial and the last isolate for amphotericin B $\left(0.062\right.$ and $0.125 \mu \mathrm{g} \mathrm{ml}^{-1}$, respectively) (Table 1). This patient was treated initially with colloidal amphotericin B (400 $\mathrm{mg} \mathrm{day}^{-1}$ i.v.) plus fluconazole $\left(800 \mathrm{mg} \mathrm{day}^{-1}\right.$ i.v.). After 5 days, colloidal amphotericin B was replaced by liposomal amphotericin B (300 $\mathrm{mg} \mathrm{day}^{-1}$ i.v.) and the dose of fluconazole was lowered $\left(400 \mathrm{mg} \mathrm{day}^{-1}\right.$ i.v.). Five days later, the treatment was continued with amphotericin B deoxycholate (75 $\mathrm{mg} \mathrm{day}^{-1}$ i.v.) and the same dosage of fluconazole ( $400 \mathrm{mg}$ day $^{-1}$ i.v.). Different formulations of amphotericin B were given for a total of 3 weeks. Fluconazole (400 $\mathrm{mg} \mathrm{day}^{-1}$ orally), as maintenance therapy, was administered for 12 months. At follow-up, the patient had recovered fully.

Mixed infections have been described in detail recently by Desnos-Ollivier et al. (2010), who observed that nearly $20 \%$ of investigated patients were infected with multiple $C$. neoformans genotypic variants. They also found that serotype A and $\mathrm{D}$ isolates can form serotype AD hybrids in vivo using a mice model. Thus, it is likely that $C$. neoformans is able to form new genotypic variants in vivo that eventually might be less susceptible to antifungal compounds. In the current study, patient 8 was found to be infected initially with an isolate belonging to genotype AFLP1B, whilst 10 days later a genotypically different isolate with genotype AFLP1 was cultured. Despite the fact that only one $C$. neoformans colony was used for further characterization, the possibility exists that the initial $C$. neoformans AFLP1B isolate underwent genotypic changes to an AFLP1 genotype due to the selection pressure caused by the antifungal treatment. This is a plausible explanation, as it has been hypothesized that $C$. neoformans genotype AFLP1A and AFLP1B strains might be hybrid genotypes (Barreto de Oliveira et al., 2004; Boekhout et al., 2001). Alternatively, the patient could be infected with multiple $C$. neoformans genotypic variants but, due to the fact that only one colony was investigated per sample, an initial mixed infection might be overlooked. This explanation has also been given for a similar observation for sequential isolates of C. neoformans from Cuban patients, where four of 19 patients were found to be probably infected by more than one $C$. neoformans genotypic variant but only a single colony was investigated (Illnait-Zaragozí et al., 2010).

In conclusion, no in vitro resistance to amphotericin B, flucytosine, fluconazole, itraconazole or voriconazole was observed among the 48 clinical C. neoformans isolates from Croatia collected between 2005 and 2010. A statistically significant correlation was not demonstrated between in vitro antifungal susceptibility patterns and the HIV status of the patients, or the mating type, serotype and AFLP genotype of the studied C. neoformans isolates. Multiple $C$. neoformans genotypic variants might exist during the initial infection and therefore it is recommended that multiple single colonies are investigated during the course of infection when a patient is not responding to the antifungal treatment.

\section{REFERENCES}

Almeida, A. M., Matsumoto, M. T., Baeza, L. C., de Oliveira e Silva, R. B., Kleiner, A. A., Melhem, M. de S., Mendes Giannini, M. J. \& Laboratory Group on Cryptococcosis (2007). Molecular typing and antifungal susceptibility of clinical sequential isolates of Cryptococcus neoformans from Sao Paulo State, Brazil. FEMS Yeast Res 7, 152-164.

Barreto de Oliveira, M. T., Boekhout, T., Theelen, B., Hagen, F., Baroni, F. A., Lazera, M. S., Lengeler, K. B., Heitman, J., Rivera, I. N. G. \& Paula, C. R. (2004). Cryptococcus neoformans shows a remarkable genotypic diversity in Brazil. J Clin Microbiol 42, 1356-1359.

Bassetti, M., Repetto, E., Mikulska, M., Miglino, M., Clavio, M., Gobbi, M., Righi, E. \& Viscoli, C. (2009). Cryptococcus neoformans fatal sepsis in a chronic lymphocytic leukemia patient treated with alemtuzumab: case report and review of the literature. J Chemother 21, 211-214.

Blasi, E., Brozzetti, A., Francisci, D., Neglia, R., Cardinali, G., Bistoni, F., Vidotto, V. \& Baldelli, F. (2001). Evidence of microevolution in a clinical case of recurrent Cryptococcus neoformans meningoencephalitis. Eur J Clin Microbiol Infect Dis 20, 535-543.

Boekhout, T., Theelen, B., Diaz, M., Fell, J. W., Hop, W. C. J., Abeln, E. C. A., Dromer, F. \& Meyer, W. (2001). Hybrid genotypes in the pathogenic yeast Cryptococcus neoformans. Microbiology 147, 891-907.

Bovers, M., Hagen, F. \& Boekhout, T. (2008). Diversity of the Cryptococcus neoformans-Cryptococcus gattii species complex. Rev Iberoam Micol 25, S4-S12.

Brandt, M. E., Pfaller, M. A., Hajjeh, R. A., Hamill, R. J., Pappas, P. G., Reingold, A. L., Rimland, D., Warnock, D. W. \& Cryptococcal Disease Active Surveillance Group (2001). Trends in antifungal drug susceptibility of Cryptococcus neoformans isolates in the United States: 1992 to 1994 and 1996 to 1998. Antimicrob Agents Chemother 45, 3065-3069.

Casadevall, A., Spitzer, E. D., Webb, D. \& Rinaldi, M. G. (1993). Susceptibilities of serial Cryptococcus neoformans isolates from patients with recurrent cryptococcal meningitis to amphotericin B and fluconazole. Antimicrob Agents Chemother 37, 1383-1386.

CLSI (2008). Reference Method for Broth Dilution Antifungal Susceptibility Testing of Yeasts. Approved Standard M27-A3. Wayne, PA: Clinical and Laboratory Standards Institute. 
Dannaoui, E., Abdul, M., Arpin, M., Michel-Nguyen, A., Piens, M. A., Favel, A., Lortholary, O., Dromer, F. \& French Cryptococcosis Study Group (2006). Results obtained with various antifungal susceptibility testing methods do not predict early clinical outcome in patients with cryptococcosis. Antimicrob Agents Chemother 50, 2464-2470.

Datta, K., Jain, N., Sethi, S., Rattan, A., Casadevall, A. \& Banerjee, U. (2003). Fluconazole and itraconazole susceptibility of clinical isolates of Cryptococcus neoformans at a tertiary care centre in India: a need for care. J Antimicrob Chemother 52, 683-686

Desnos-Ollivier, M., Patel, S., Spaulding, A. R., Charlier, C., GarciaHermoso, D., Nielsen, K. \& Dromer, F. (2010). Mixed infections and in vivo evolution in the human fungal pathogen Cryptococcus neoformans. mBio 1, e00091.

Fries, B. C. \& Casadevall, A. (1998). Serial isolates of Cryptococcus neoformans from patients with AIDS differ in virulence for mice. J Infect Dis 178, 1761-1766.

Guinea, J., Hagen, F., Peláez, T., Boekhout, T., Tahoune, H., TorresNarbona, M. \& Bouza, E. (2010). Antifungal susceptibility, serotyping, and genotyping of clinical Cryptococcus neoformans isolates collected during 18 years in a single institution in Madrid, Spain. Med Mycol 48, 942-948.

Hagen, F., Illnait-Zaragozi, M. T., Bartlett, K. H., Swinne, D., Geertsen, E., Klaassen, C. H., Boekhout, T. \& Meis, J. F. (2010). In vitro antifungal susceptibilities and amplified fragment length polymorphism genotyping of a worldwide collection of 350 clinical, veterinary and environmental Cryptococcus gattii isolates. Antimicrob Agents Chemother 54, 5139-5145.

Illnait-Zaragozi, M. T., Martínez, G. F., Curfs-Breuker, I., Fernández, C. M., Boekhout, T. \& Meis, J. F. (2008). In vitro activity of the new azole isavuconazole (BAL4815) compared with six other antifungal agents against 162 Cryptococcus neoformans isolates from Cuba. Antimicrob Agents Chemother 52, 1580-1582.

Illnait-Zaragozí, M. T., Martínez-Machín, G. F., Fernández-Andreu, C. M., Hagen, F., Boekhout, T., Klaassen, C. H. W. \& Meis, J. F. (2010). Microsatellite typing and susceptibilities of serial Cryptococcus neoformans isolates from Cuban patients with recurrent cryptococcal meningitis. BMC Infect Dis 10, 289.

Kidd, S. E., Hagen, F., Tscharke, R. L., Huynh, M., Bartlett, K. H., Fyfe, M., Macdougall, L., Boekhout, T., Kwon-Chung, K. J. \& Meyer, W. (2004). A rare genotype of Cryptococcus gattii caused the cryptococcosis outbreak on Vancouver Island (British Columbia, Canada). Proc Natl Acad Sci U S A 101, 17258-17263.

Kwon-Chung, K. J., Boekhout, T., Fell, J. W. \& Diaz, M. (2002). Proposal to conserve the name Cryptococcus gattii against $C$. hondurianus and C. bacillisporus (Basidiomycota, Hymenomycetes, Tremellomycetidae). Taxon 51, 804-806.

López-Jodra, O., Torres-Rodríguez, J. M., Méndez-Vásquez, R., Ribas-Forcadell, E., Morera-López, Y., Baró-Tomás, T. \& AliaAponte, C. (2000). In vitro susceptibility of Cryptococcus neoformans isolates to five antifungal drugs using a colorimetric system and the reference microbroth method. J Antimicrob Chemother 45, 645-649.

Meyer, W., Aanensen, D. M., Boekhout, T., Cogliati, M., Diaz, M. R., Esposto, M. C., Fisher, M., Gilgado, F., Hagen, F. \& other authors (2009). Consensus multi-locus sequence typing scheme for Cryptococcus neoformans and Cryptococcus gattii. Med Mycol 47, 561-570.
Park, B. J., Wannemuehler, K. A., Marston, B. J., Govender, N., Pappas, P. G. \& Chiller, T. M. (2009). Estimation of the current global burden of cryptococcal meningitis among persons living with HIV/ AIDS. AIDS 23, 525-530.

Perfect, J. R., Dismukes, W. E., Dromer, F., Goldman, D. L., Graybill, J. R., Hamill, R. J., Harrison, T. S., Larsen, R. A., Lortholary, O. \& other authors (2010). Clinical practice guidelines for the management of cryptococcal disease: 2010 update by the Infectious Diseases Society of America. Clin Infect Dis 50, 291-322.

Perkins, A., Gomez-Lopez, A., Mellado, E., Rodriguez-Tudela, J. L. \& Cuenca-Estrella, M. (2005). Rates of antifungal resistance among Spanish clinical isolates of Cryptococcus neoformans var. neoformans. $J$ Antimicrob Chemother 56, 1144-1147.

Pfaller, M. A., Zhang, J., Messer, S., Tumberland, M., Mbidde, E., Jessup, C. \& Ghannoum, M. (1998). Molecular epidemiology and antifungal susceptibility of Cryptococcus neoformans isolates from Ugandan AIDS patients. Diagn Microbiol Infect Dis 32, 191-199.

Pfaller, M. A., Messer, S. A., Boyken, L., Rice, C., Tendolkar, S., Hollis, R. J., Doern, G. V. \& Diekema, D. J. (2005). Global trends in the antifungal susceptibility of Cryptococcus neoformans (1990 to 2004). J Clin Microbiol 43, 2163-2167.

Souza, L. K., Fernandes, O. F., Kobayashi, C. C. B. A., Passos, X. S., Costa, C. R., Lemos, J. A., Souza-Júnior, A. H. \& Silva, M. R. (2005). Antifungal susceptibilities of clinical and environmental isolates of Cryptococcus neoformans in Goiânia city, Goiás, Brazil. Rev Inst Med Trop Sao Paulo 47, 253-256.

Spitzer, E. D., Spitzer, S. G., Freundlich, L. F. \& Casadevall, A. (1993). Persistence of initial infection in recurrent Cryptococcus neoformans meningitis. Lancet 341, 595-596.

Sullivan, D., Haynes, K., Moran, G., Shanley, D. \& Coleman, D. (1996). Persistence, replacement, and microevolution of Cryptococcus neoformans strains in recurrent meningitis in AIDS patients. $J$ Clin Microbiol 34, 1739-1744.

Tortorano, A. M., Viviani, M. A., Rigoni, A. L., Cogliati, M., Roverselli, A. \& Pagano, A. (1997). Prevalence of serotype D in Cryptococcus neoformans isolates from HIV positive and HIV negative patients in Italy. Mycoses 40, 297-302.

van Elden, L. J., Walenkamp, A. M., Lipovsky, M. M., Reiss, P., Meis, J. F., de Marie, S., Dankert, J. \& Hoepelman, A. I. (2000). Declining number of patients with cryptococcosis in the Netherlands in the era of highly active antiretroviral therapy. AIDS 14, 2787-2788.

Vigouroux, S., Morin, O., Milpied, N., Mahé, B., Rapp, M. J. \& Harousseau, J. L. (2000). [Cryptococcus neoformans infection in hematologic malignancies]. Rev Med Interne 21, 955-960 (in French).

Viviani, M. A., Cogliati, M., Esposto, M. C., Lemmer, K., Tintelnot, K., Colom Valiente, M. F., Swinne, D., Velegraki, A., Velho, R. \& European Confederation of Medical Mycology (ECMM) Cryptococcosis Working Group (2006). Molecular analysis of 311 Cryptococcus neoformans isolates from a 30-month ECMM survey of cryptococcosis in Europe. FEM Yeast Res 6, 614-619.

Warkentien, T. \& Crum-Cianflone, N. F. (2010). An update on Cryptococcus among HIV-infected patients. Int J STD AIDS 21, 679-684. 